Gelis tarihi / Received: Kasım / November 18, 2009

Düzelti sonrası kabul tarihi / Accepted after revision: Ocak / January 30, 2010

Online yaym tarihi / Published online: Mart / March 26, 2010

doi: $10.2399 /$ tao.09.023

\title{
ARAŞTIRMA / RESEARCH ARTICLE \\ Obstrüktif uyku apne sendromlu hastalarda klinik hikaye ve fizik muayene bulgularının apne-hipopne indeksi ile ilişkisi
}

I. Akın, M. Sağıt, N. Salman, İ.H. Fırat

\section{Relationship between clinical history and physical examination findings and apnea hypopnea index in patients with obstructive sleep apnea syndrome}

Objectives: The aim of this study was to investigate the correlation between clinical history, physical examination results and apnea hypopnea index (AHI) in patients with suspected obstructive sleep apnea syndrome (OSAS).

Methods: We evaluated 110 patients who admitted to our clinic with a primary complaint of snoring and witnessed apnea. Demographic data including age, sex, body mass index (BMI) and neck circumference were recorded. Patients' medical history was recorded and all of them completed an Epworth sleepiness scala (ESS) questionnaire. Their flexible fiberoptic nasopharyngoscopy by Muller maneuver and modified Mallampati scores (MMS) were recorded during otorhinolaryngologic evaluation. Then patients underwent overnight polysomnography. The $\mathrm{AHI}$ is used to classify the severity of sleep apnea into the following categories: Group 1; an AHI of 0 to 5 indicates that simple snoring, Group 2; an AHI of 5-15 is considered mild sleep apnea, Group 3: an AHI of 15-30 is moderate sleep apnea, Group 4: an AHI of $>30$ is severe sleep apnea. The correlation between BMI, neck circumference, ESS scores, modified Mallampati scores and Muller maneuver results and group categories were investigated.

Results: There were statistically significant differences between the groups for neck circumferences, ESS scores and retropalatal narrowing grade in Muller maneuver. There were

Dr. İstemihan Akın, Dr. Nergis Salman

T.C. SB Dışkapı Yıldırım Beyazıt Ĕ̆itim ve Araştırma Hastanesi 1. KBB Kliniği, Ankara Dr. Mustafa Sağıt

T.C. SB Şanlıurfa Eğitim ve Araştırma Hastanesi KBB Kliniği, Şanlıurfa Dr. İbrahim Hikmet Fırat

T.C. SB Dışkapı Yildırım Beyazıt Eğitim ve Araștırma Hastanesi Göğüs Hastalıklar Kliniği, Ankara no statistically significant differences between the groups for BMI, modified Mallampati scores and tongue base narrowing grade in Muller maneuver. There was significant correlation between the $\mathrm{AHI}$ and neck circumference, ESS scores, modified Mallampati scores, retropalatal and tongue base narrowing grade in Muller maneuver, however it was found that only ESS score was an independent variable for $\mathrm{AHI}$.

Conclusion: When patients who applied to ENT clinics for primary complaint of snoring and witnessed apnea have high ESS scores and high obstruction grades in Muller maneuver, they should be directed sleep laboratory and be prioritized for polysomnographic examination since they may have an increased OSAS risk.

Key Words: Sleep apnea, Epworth sleepiness scala, Muller maneuver.

Turk Arch Otolaryngol, 2010; 48(1): 21-27

\section{Özet}

Amaç: Obstrüktif uyku apne sendromu (OUAS) şüphesi olan hastalarda klinik hikaye ve fizik muayene bulgularının apne-hipopne indeksi (AHI) ile ilişkilerinin araştırılması amaçlanmıştır.

Yöntem: Horlama ve/veya tanıklı apne şikayetiyle kliniğimize başvuran 110 hastanın klinik hikayelerinde yaş, cinsiyet, antropometrik ölçümleri, Epworth uykululuk skala skorları (EUS) kaydedildi. Kulak burun boğaz muayeneleri sırasında modifiye Mallampati skorları (MMS) ve fleksibl nazofarengoskopi ile Müller manevrası sonuçları kaydedildi. Tüm hastalara gecelik polisomnografi yapılarak hastalar $\mathrm{AHI}$ göre 4 gruba ayrıldı: Grup 1: $\mathrm{AHI}$ $\leq 5$ basit horlama, Grup 2: AHI 5-15 hafif derecede OUAS, Grup 3: AHI 15-30 arasında olan orta derecede OUAS, Grup 4: AHI >30 olanlar ağır derecede OUAS olarak sınıflandırıldı. Vücut-kit- 
le indeksi (VKI), boyun çevresi (BÇ), EUS, MMS ve Müller manevrası sonuçlarıyla gruplar arasındaki ilişki araştırıldı.

Bulgular: BÇ, EUS ve Müller manevrasında retropalatal bölgedeki obstrüksiyon derecesi açısından gruplar karşılaştırıldığında istatistiksel olarak anlamlı farklılık tespit edildi. VKI, MMS ve Müller manevrasında dil kökü bölgesindeki obstrüksiyon derecesi ile gruplar arasında istatistiksel olarak anlamlı bir ilişki saptanmadı. AHI ile BÇ, EUS, MMS, Müller manevrasındaki retropalatal ve dil kökü bölgesindeki obstrüksiyon derecesi arasında pozitif bir korelasyon olduğu tespit edildi ancak AHI için bağımsız değişkenin sadece EUS skoru olduğu tespit edildi.

Sonuç: Horlama ve/veya tanıklı apne şikayetiyle KBB polikliniklerine başvuran hastalarda klinik hikaye ve fizik muayene sırasında EUS skorları ve Müller manevrasında obstrüksiyon derecesi yüksek olarak saptanan hastalar uyku laboratuvarlarına yönlendirilmeli ve bu hastaların OUAS olma olasılığı yüksek olduğu için polisomnografi tetkikinde öncelik verilmelidir.

Anahtar Sözcükler: Uyku apnesi, Epworth uykululuk skalası, Müller manevrası.

Türk Otolarengoloji Arşivi, 2010; 48(1): 21-27

\section{Giriş}

Obstrüktif uyku apne sendromu (OUAS), uyku sırasında tekrarlayan üst solunum yolu tıkanmaları ve buna bağlı kan oksijen saturasyonunda düşme ile karakterize bir sendromdur. ${ }^{1}$ Horlama, ağzı açık uyuma, gece apneleri, gün içi aşırı uykuya eğilim hali OUAS'nin esas semptomlaridır. Basit horlama genel populasyonun \%30-50'sinde görülmesine rağmen OUAS'nin görülme sıklığ1 \%2-4'tür. ${ }^{2}$ Horlama şikayetiyle kulak burun boğaz polikliniklerine başvuran hastalarda basit horlama ile OUAS ayırımının yapılabilmesi uygun tedavi planlanması açısından son derece önemlidir.

\footnotetext{
*Epworth Uykululuk Skalasının Türkçe Versiyonu

Son zamanlarda, günlük yaşantınız içinde, aşağıda belirtilen durumlarda hang sıklıkla uyuklarsınız (buradan yorgun hissetmek değil, uyuklamak veya uyuyakalmak anlaşılmalıdır) Bu şeylerden birini son zamanlarda yapmamış olsanız bile, böyle bir durumun, sizi nasıl etkileyeceğini düşünmeye çalışarak cevap veriniz. Ölçekteki her bir DURUM için, aşağıdaki ifadelere karşılık gelen sayılardan, sizin için en uygununu isaretleyiniz.

0: Hiçbir zaman uyuklamam

1: Nadiren uyuklarım

2: Zaman zaman uyuklarım

3: Büyük olasılıkla uyuklarım
}

OUAS hastaların değerlendirilmesinde klinik hikaye ve fizik muayene bulguları önemli yer tutar. Bununla birlikte OUAS tanısında kullanılan altın standart yöntem polisomnografidir (PSG). ${ }^{1}$ Ancak hasta uyumundaki bozukluklar, teknik eleman gerektirmesi, maliyetinin yüksek olması, belirli merkezlerde yap1lıyor olması ve hastaların tetkik için uzun süre beklemesi gibi nedenler PSG tetkikinin kullanımını kısıtlamaktadır. Bu yüzden PSG'ye alternatif olabilecek yöntemler geliştirilmeye çalışılırken bunun yanısıra hastaların klinik, antropometrik ve epidemiyolojik parametreleriyle AHİnin tahmin edilebilirlik değerlerini gösteren çalışmalara ihtiyaç vardır.

Bu çalışmada OUAS şüphesi olan hastalarda klinik hikaye ve fizik muayene bulgularının apne-hipopne indeksi (AHİ) ile ilişkileri ve OUAS varlığını tahmin ettirmedeki etkinliklerinin araştırılması amaçlanmıştır.

\section{Gereç ve Yöntem}

\section{Hasta seçimi}

Bu çalışma horlama ve/veya tanıklı apne şikayetiyle kliniğimize başvuran 110 hastayı kapsamaktadır. Bütün hastalar çalışma hakkında ayrıntılı olarak bilgilendirilerek bilgilendirilmiş onam formu alındi. Hastaların şikayet süreleri, yaş, cinsiyet, boy, vücut ağırlı̆̆1 gibi demografik verileri kaydedildi. Hastaların klinik hikayelerinde gün içi uyuklama halini degerlendirmek için Epworth uykululuk skala (EUS) skorunun Türkçe versiyonu* kullanılarak sonuçlar 0-24 arasında olacak şekilde kaydedildi.

\begin{tabular}{lcccc} 
Durum & Uyuklama Olasılığım \\
\hline 1 Oturmuş birşeyler okurken & 0 & 1 & 2 & 3 \\
2 Televizyon seyrederken & 0 & 1 & 2 & 3 \\
3 Toplum içinde hareketsizce otururken (örneğin: herhangi bir & 0 & 1 & 2 & 3 \\
$\quad$ toplantıda veya tiyatro gibi yerlerde) & & & & \\
4 Ara vermeden en az bir saat süren bir araba yolculuğunda yolcu & 0 & 1 & 2 & 3 \\
$\quad$ olarak bulunurken & & & & \\
5 Öğleden sonra koşullar uygun olduğunda, dinlenmek için uzanmışken & 0 & 1 & 2 & 3 \\
6 Birisiyle oturmuş konuşurken & 0 & 1 & 2 & 3 \\
7 Alkol almadığım bir öğle yemeğinden sonra sessizce otururken & 0 & 1 & 2 & 3 \\
8 lçinde olduğum araba, trafikte birkaç dakika için durduğunda & 0 & 1 & 2 & 3 \\
Toplam Skor & & & & \\
\hline
\end{tabular}


Hastaların antropometrik ölçümleri yapıldı. Bunun için vücut ağırlığının boyun karesine oranıyla vücut kitle indeksi (VKİ) ve krikotiroid membran seviyesinden yapılan ölçümle boyun çevresi (BÇ) ölçümleri kaydedildi.

\section{KBB muayenesi}

Orofarinks muayenesinde uvula, yumuşak damak ve lateral farengeal bantların görünümü, tonsil hipertrofisi olup olmadığ1 ve dil kökünün yumuşak damak ile ilişkisini ortaya koyan modifiye Mallampati skorları (MMS) kaydedildi.

Nazal muayene sırasında nazal pasajı kapatacak şekilde septum deviasyonu olan olgular veya nazal polipozis gibi nazal patoloji saptanan olgular ve kraniofasial anomalisi olan olgular çalışmaya dahil edilmedi.

\section{Müller manevrası}

Üst hava yollarındaki kollaps bölgelerinin değerlendirilmesi amaciyla fleksibl nazofarengoskopi ile hasta oturur pozisyonda iken Müller manevrası yapıld1. Müller manevrasında ağız ve burun kapalı iken zorlu inspiryum sırasında retropalatal bölge ve dil kökündeki kollaps alanları tespit edilip obstrüksiyon derecesi yüzde olarak ifade edilip kaydedildi.

\section{Polisomnografi}

Bütün hastalara hastanemiz Gögüs Hastalıkları Kliniğine bağlı uyku merkezinde nokturnal PSG yapild. Hastaların uyku evreleri, oksijen saturasyonlar1, saatte olan apne ve hipopne sayıları kaydedildi. Apne, 10 sn veya daha fazla süreyle ağ1z ve burunda hava akımının durmasıdır. Hipopne, hava akımında 10 sn veya daha fazla süreyle en az \%50 azalma ile birlikte, oksijen saturasyonunda \%3'lük düşme veya arousal gelişimidir. Apne-Hipopne indeksi (AHİ) ise uyku sirasinda meydana gelen apne ve hipopnelerin toplam sayısının uyku süresine (saat olarak) bölünerek bulunan sayıdır.
Hastalar AHI'lerine göre 4 gruba ayrild1; Grup 1: AHİ $\leq 5$ basit horlama, Grup 2: AHİ 5-15 hafif derecede OUAS, Grup 3: AHİ 15-30 arasinda olan orta derecede OUAS, Grup 4: AHİ >30 olanlar ağ1r derecede OUAS olarak sınıflandırıldı. Vücut-kitle indeksi, boyun çevresi, Epworth uykululuk skala skoru, modifiye Mallampati skoru ve Müller manevrası sonuçlarıyla gruplar arasındaki ilişki araştırıldı.

\section{İstatistiksel analiz}

İstatistiksel olarak SPSS-11 versiyonu kullanıld1 ve sonuçlar ortalama \pm SD olarak ifade edildi. Gruplar arasındaki ilişki için tek yönlü varyans analizi (one way anova) testi ve Post-hoc test olarak Bonferroni testi kullanıldi. AHİ belirleyicilerini saptamak amaciyla Pearson korelasyon testi ve AHİ'nin bağımsız belirleyicilerini saptamak amaciyla lineer regresyon analizi kullanıldı. $\mathrm{P}<0.05$ olması istatistiksel olarak anlamlı kabul edildi.

\section{Bulgular}

Hastalar 86 (\%78.2) erkek, 24 (\%21.8) kadın olmak üzere 110 hastadan oluşmaktadır ve ortalama yaş 46.7 99.8 'dir. Hastaların ortalama şikayet süresi $67.3 \pm 37.8$ aydir. Ortalama VKI'’i $29.3 \pm 4.3$ ve BÇ'si ortalamas1 $41.0 \pm 3.8 \mathrm{~cm}$ olarak saptand1. Epworth uykululuk skala skorları ortalamas1 ise $11.7 \pm 6.0$ olarak saptand1.

KBB muayenesinde orofarinkste uvula görünümü hastaların \%30.4'ünde normal görünümde, \%28.2'sinde hafif elonge, \%40.9'unda belirgin elonge izlendi. Tonsiller ise hastaların \%55.5'inde Evre 0, \%33.6'sinda Evre 1, \%10.9'unda Evre 2 hipertrofik olarak saptandi. Lateral farengeal bantlar hastaların \%20'sinde normal görünümde, \% 75.5'inde hafif kollabe, \%4.5'inde ise belirgin kollaps oldugu izlendi. Dil kökünün yumuşak damak ile ilişkisini ortaya koyan modifiye Mallampati skorlar1 ortalamas1 ise 1.2 \pm 0.4 olarak saptand1. Yapılan Müller manevrasın- 
da ise retropalatal bölgede obstrüksiyon derecesi ortalama $\% 72.2 \pm 13.9$, dil kökünde ise \%23.1 \pm 18.7 olarak tespit edildi.

Yapilan polisomnografi sonrası hastaların AHI'leri 0.5-94.4 arasında değişmekle beraber ortalama 17.9 \pm 15.8 idi. Hastalar AHI'lerinin şiddetine göre gruplandırıldıklarında hastaların \%20.9'u Grup 1'de, \%32,7'si Grup 2'de, \%30.0'1 Grup 3'te, \%16.4'ü Grup 4'te yer almaktaydi. Grupların herbirisinin VKİ, boyun çevresi, Epworth uykululuk skala skorlar1, modifiye Mallampati skorları, Müller manevrasinda retropalatal bölgedeki ve dil kökündeki obstrüksiyon derecelerinin ortalamaları Tablo 1'de gösterilmiştir.

Boyun çevresi, Epworth uykululuk skala skoru ve Müller manevrasında retropalatal bölgedeki obstrüksiyon derecesi açısından gruplar karşılaştırıld1ğında istatistiksel olarak anlamlı farklilık tespit edildi ( $<<0.05)$ (Tablo 1). VKİ, Modifiye Mallampati skoru ve Müller manevrasinda dil kökü bölgesindeki obstrüksiyon derecesi ile gruplar arasında istatistiksel olarak anlamlı bir ilişki saptanmadı ( $p>0.05)$ (Tablo 1).

AHİ ile demografik veriler, antropometrik ölçümler, Epworth uykuluk skala skorları ve fizik muayene bulgularının ilişkisi Pearson korelasyon testi ve lineer regresyon analizi ile araştırıldı ve sonuçlar Tablo 2'de özetlenmiştir.
AHİ ile BÇ, EUS, MMS, Müller manevrasındaki retropalatal ve dil kökü bölgesindeki obstrüksiyon derecesi arasinda pozitif bir korelasyon oldugu tespit edilmiş ancak lineer regresyon analizi AHİ için bağımsız değişkenin sadece EUS skoru olduğu tespit edilmiştir.

AHİ ile EUS skoru arasındaki ilişki Şekil 1'de gösterilmiştir.

\section{Tartışma}

OUAS, uyku sirasinda tekrarlayan üst solunum yollarında tıkanma ve buna bağl1 kan $\mathrm{O}_{2}$ saturasyonunda düşme ile karakterize bir sendromdur ve uykudaki solunum bozukluklarının \%90-95'ini oluşturur. ${ }^{1}$ OUAS yaygin görülen bir sağlik sorunu olup tanisında kullanılan altın standart yöntem PSG'dir., ${ }^{1,3}$ Bununla birlikte klinik hikaye ve fizik muayene OUAS teşhisinde önemlidir. ${ }^{4,5}$ Klinik hikayede horlama, uykusuzluk, konsantrasyon veya dikkat azalması, gün içi uykuya meyil olup olmadığı sorgulanmalıdır.

Gün içi uykuya meyli sorgulamak için sıklıkla Epworth uykululuk skalasından faydalanılır. Pastör ve ark. tek başına klinik hikayenin uyku hastalıkları teşhisinde yeterli olmadı̋̆ını ifade etmişlerdir. ${ }^{6}$ Gondin ve ark. klinik şikayet, Epworth uykuluk skalası skorları ve VKİ ile PSG sonuçlarını karşılaştırmışlar, istatistiksel olarak anlamlı fark bulamamışlardır. ${ }^{7} \mathrm{Bu}-$ nunla birlikte İzci ve ark. OUAS araştırılmasında

Tablo 1. VKI, BÇ, EUS, MMS, Müller manevrasındaki retropalatal ve dil kökü bölgesindeki obstrüksiyon derecesi açısından gruplar arasındaki ilişki.

\begin{tabular}{|c|c|c|c|c|c|c|}
\hline & VKi & BÇ & EUS & MMS & Retropalatal* & Dil Kökü \\
\hline Grup 1 & $27.3 \pm 4.9$ & $37.6 \pm 3.8^{+}$ & $9.5 \pm 7.1$ & $1.2 \pm 0.4$ & $66.0 \pm 13.7$ & $18.6 \pm 18.9$ \\
\hline Grup 2 & $30.1 \pm 4.3$ & $41.6 \pm 3.5$ & $10.6 \pm 5.9$ & $1.2 \pm 0.4$ & $71.1 \pm 14.6$ & $23.0 \pm 19.5$ \\
\hline Grup 3 & $29.9 \pm 4.1$ & $42.2 \pm 3.3$ & $12.5 \pm 4.3$ & $1.1 \pm 0.3$ & $75.6 \pm 13.2$ & $21.5 \pm 14.8$ \\
\hline Grup 4 & $29.1 \pm 3.2$ & $42.0 \pm 2.9$ & $15.5 \pm 3.6^{\neq}$ & $1.4 \pm 0.5$ & $76.1 \pm 11.4$ & $32.2 \pm 21.5$ \\
\hline$P$ değeri & 0.073 & $0.000 \S$ & $0.006 \S$ & 0.232 & $0.042 \S$ & 0.121 \\
\hline
\end{tabular}

*: Müller manevrasında retropalatal bölgedeki obstrüksiyon derecesi ile gruplar arasında istatistiksel olarak anlamlı bir ilişki saptandı, ancak ikili gruplar arasında fark saptanmadı. ${ }^{B}$ BÇ açısından Grup 1 ile Grup 2, 3 ve 4 arasında istatistiksel olarak anlamlı farklılık mevcut. Grup 1-2 (p değeri 0.000), Grup 1-3 (p değeri 0.000), Grup 1-4 (p değeri 0.001); „EUS skoru açısından Grup 4 ile Grup 1 ve 2 arasında istatistiksel olarak anlamlı farklılık mevcut. Grup 1-4 ( $p$ değeri 0.008), Grup 2-4 ( $p$ değeri 0.025); §Istatistiksel olarak anlamlı değişiklik $p<0.05$. 
EUS skorunun Türkçe versiyonunun güvenilir ve değerli bir parametre olduğunu ifade etmişlerdir. ${ }^{8}$ Karakoç ve ark. EUS skoru ile AHI arasında pozitif bir korelasyon olduğunu saptamışlar ve OUAS olan hastaların gündüz uykululuk halinin değerlendirilmesinde EUS skorunun kullanılabileceğini ifade etmişlerdir. ${ }^{9}$ Bu çalışmada ise Epworth uykululuk skala skorları ile AHİ değerine göre yapılan gruplar arasında istatistiksel olarak anlamlı bir ilişki saptanmıştır ve bu ilişkinin Grup 4 ile Grup 1 ve 2 arasındaki istatistiksel olarak farklılıktan kaynaklandığı tespit edilmiştir. Pearson korelasyon analizi ile AHİ değeri ile EUS arasında güçlü bir ilişki olduğu saptanmış ve lineer regresyon analizi ile AHİ için bağımsız değişkenin parametrelerimiz arasinda sadece EUS oldugu saptanmıştır.
Tablo 2. AHI'nin yaş, VKI, BÇ, EUS skoru, MMP skoru, Müller manevrasındaki retropalatal ve dil kökü bölgesindeki obstrüksiyon derecesi ile ilişkisi.

\begin{tabular}{lcccc}
\hline & $\mathbf{r}$ & $\mathbf{p}$ & Beta & $\mathbf{P}$ \\
\hline Yaş & 0.117 & 0.223 & - & - \\
VKI & 0.073 & 0.449 & - & - \\
BÇ & 0.299 & 0.001 & 0.171 & 0.076 \\
EUS & 0.339 & 0.000 & 0.224 & $0.020^{*}$ \\
MMP & 0.242 & 0.011 & 0.123 & 0.202 \\
Retropalatal & 0.255 & 0.007 & 0.083 & 0.451 \\
Dil kökü & 0.279 & 0.003 & 0.067 & 0.562 \\
\hline
\end{tabular}

*AHI için bağımsız değişken EUS $(p<0.05)$.

KBB muayeneleri sırasında hastaların ayrica VKI ve $\mathrm{BC}$ gibi antropometrik ölçümleri de yapılmalıdır. Hoffstein ve ark. VKİ ve BÇ ile AHİ arasında güçlü bir korelasyon olduğunu ifade etmişlerdir. ${ }^{10} \mathrm{Bu}$ ça-

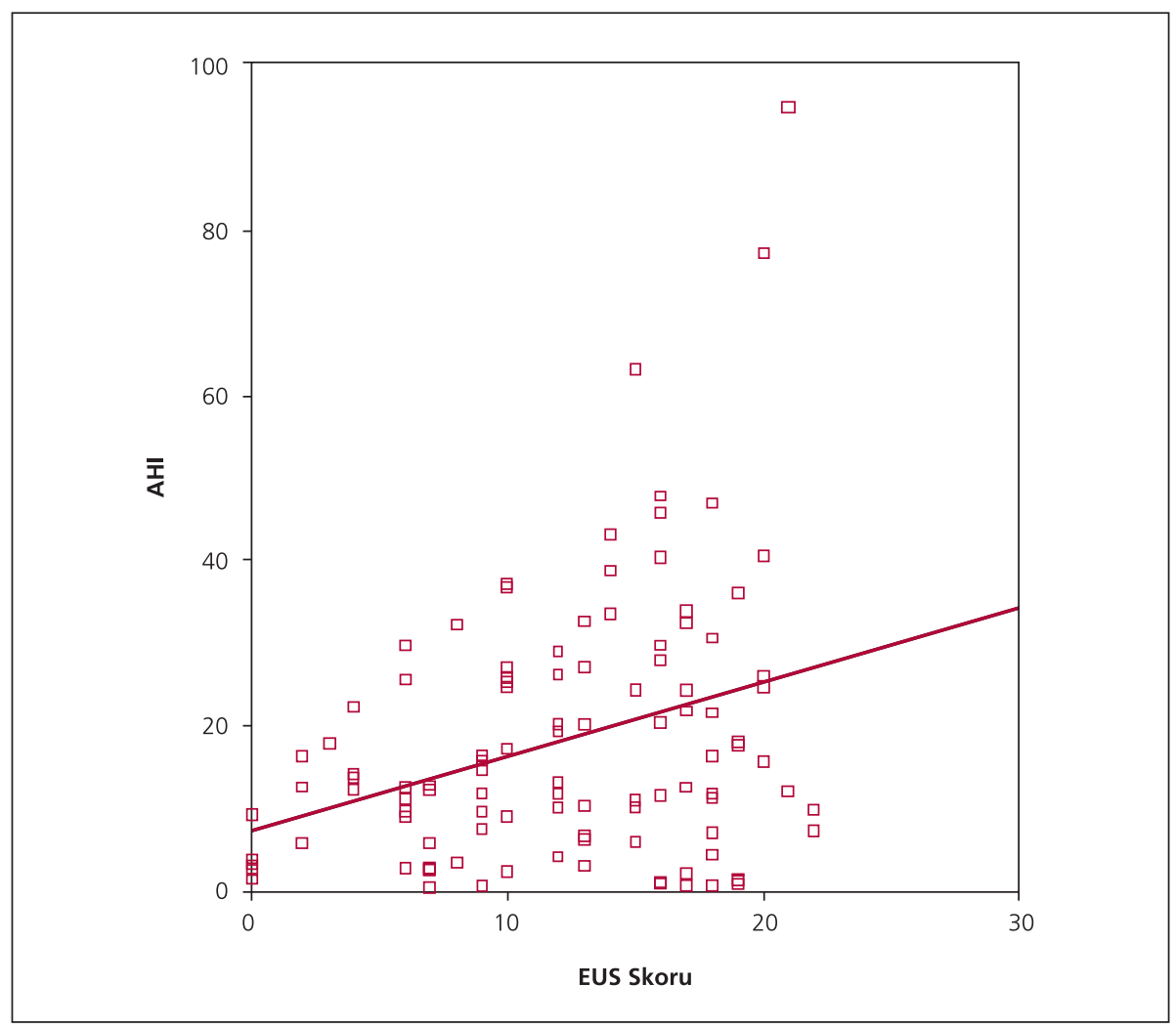

Şekil 1. AHI ile EUS skoru arasındaki ilişki. [Bu şekil, derginin www.turkarchotolaryngol.org adresindeki online versiyonunda renkli görülebilir] 
lışmada ise BÇ ölçümleri ile gruplar arasında istatistiksel olarak anlamlı bir ilişki saptanmıştır ve bu ilişkinin Grup 1 ile diğer 3 grup arasındaki istatistiksel farklılıktan kaynaklandığ tespit edilmiştir. VKİ ile gruplar arasında istatistiksel olarak anlamlı bir ilişki saptanmamıştır. BÇ ile AHİ arasında bir korelasyon olduğu tespit edilmiştir, ancak lineer regresyon analizi ile BÇ’nin AHI'nin bağımsız bir değişkeni olmadığı saptanmıştır.

Nazofarengoskopi ile Müller manevrası ilk kez Borowiecki ve ark. tarafından tarif edilmiştir. ${ }^{11}$ Kolay uygulanabilmesi, ucuz olması, minimal invaziv olmas1, operasyon öncesi ve sonrası tekrarlanabilir olmas1, güvenilir olması gibi avantajları mevcuttur. ${ }^{12} \mathrm{Bu}-$ nun yanı sıra yapan kişi açısından sübjektif bir test olması, retroglossal bölgedeki değişiklikleri retropalatal bölgeye göre daha az göstermesi gibi dezavantajlar1 mevcuttur. ${ }^{13,14}$ Bununla birlikte Terris ve ark. Müller manevrasının sübjektif olmakla birlikte doğruluk derecesinin yapan kişinin deneyimiyle bağlantılı olmadığını ifade etmişlerdir. ${ }^{12}$ Müller manevrası ile ilgili diğer bir eleştiride manevranın uyanıkken yapılmas1 ve uykuda olan farengeal bölgedeki dinamik değişiklikleri tam olarak yansıtamayacağ1 yönündedir. ${ }^{15}$ Biz Müller manevrasını oturur pozisyonda yaptık, çünkü bazı yazarlar oturur ve yatar pozisyonda yapılan Müller manevrasında farengeal kollapsibilite aç1sından fark olmadığını ifade etmişlerdir. ${ }^{16}$

Müller manevrası ile anatomik darlık saptanan bölgeler ile OUAS şiddetini ortaya koyan birçok çalışma mevcuttur. Pang ve ark. OUAS şiddeti ile dil kökündeki obstrüksiyon şiddeti arasında güçlü bir ilişki oldugunu saptamışlardır. ${ }^{17}$ Hori ve ark. ise retropalatal bölgedeki obstrüksiyon ile AHİ arasında önemli bir ilişki olduğunu saptamışlardır. ${ }^{18} \mathrm{Bu}$ çalışmada da Müller manevrasında retropalatal bölgedeki obstrüksiyon derecesi ile gruplar arasında istatistiksel olarak anlamlı bir ilişki saptanırken, dil kökündeki obstrüksiyon derecesi ile gruplar arasında istatistiksel olarak anlamlı bir ilişki saptanmadı. AHİ ile retropalatal bölgedeki ve dil kökündeki obstrüksiyon derecesi arasında bir korelasyon saptanırken, bunların AHİ için tek başlarına bağımsız bir değişken olmadıkları tespit edilmiştir.

OUAS tanısında altın standart yöntem PSG'dir. Ancak belirli merkezlerde yap1lyor olması ve hastaların tetkik için uzun süre beklemesi gibi nedenlerle bir yandan PSG'ye alternatif olabilecek yöntemler geliştirilmeye çalışılırken diğer yandan hastaların klinik, antropometrik ve epidemiyolojik parametreleriyle AHI'nin tahmin edilebilirlik değerlerini gösteren çalışmalar yapılmaktadır. Montoya ve ark. OUAS'li 433 hastada yaptıkları çalışmada hastaların klinik Özellikleri ile AHİ arasında bir korelasyon oldugunu saptamışlar ve lokal regresyon analizi ile AHİ değerini saptamak için bir formül üretmişlerdir. Bu formülün sensitivitesinin $\% 74.6$, spesifitesinin \%66.3 olarak bildirmisslerdir. ${ }^{19}$ Sharma ve ark. 102 hasta üzerinde yaptıkları çalışmada hastaların yaş, cinsiyet, VKİ, horlama indeksi, uykuda olan boğulma hissi indeksi ile AHİ skoru arasinda lokal regresyon analizi ile bir formül üretmişler ve sensitivitesinin \%91.3, spesifitesinin \%68.5 olduğunu ifade etmişlerdir. ${ }^{20}$ Bununla birlikte Schafer ve ark. 40 hasta üzerinde yaptıkları çalışmada hastaların klinik özellikleri ile AHİ arasında bir korelasyon saptamadiklarını belirtmişlerdir. ${ }^{21}$ Bizim çalışmamızda da EUS, BÇ ve Müller manevrasında retropalatal bölgedeki obstrüksiyon derecesi ile AHI'ne göre yapılan gruplar arasında istatistiksel olarak anlamlı ilişki saptanmıştır. BÇ, EUS, MMS, retropalatal ve dil kökü bölgesindeki obstrüksiyon derecesi ile AHİ arasında korelasyon olduğu tespit edilmiş, ancak AHİ için tek bağımsız değişkenin EUS olduğu saptanmıştır.

\section{Sonuç}

Horlama ve/veya tanıklı apne şikayetiyle KBB polikliniklerine başvuran hastalarda klinik hikaye ve fizik muayene sırasında antropometrik ölçümlerin yanı sıra Epworth uykululuk skala skorları kaydedil- 
melidir. Fizik muayenenin bir parçası olarak Müller manevrası ile retropalatal bölgedeki ve dil kökündeki obstrüksiyon derecesi kaydedilmelidir. EUS skorlar1 ve Müller manevrasında obstrüksiyon derecesi yüksek olarak saptanan hastalar uyku laboratuvarlarına yönlendirilmeli ve bu hastaların OUAS olma olasılığ1 yüksek olduğu için PSG tetkikinde öncelik verilmelidir.

\section{Kaynaklar}

1. Guilleminault C. Clinical features and evaluation of obstructive sleep apnea. In: Kryger MH, Roth T, Dement WC, eds. Principles and practice of sleep medicine. Philadelphia: W.B. Saunders; 1989. p. 552-8.

2. Young T, Palta M, Dempsey J, Skatrud J, Weber S, Badr S. The occurrence of sleep-disordered breathing among middle-aged adults. $N$ Engl J Med 1993; 328: 1230-5.

3. Phillipson EA. Sleep apnea-a major public health problem. $N$ Engl J Med 1993; 328: 1271-3.

4. Olejniczak PW, Fisch BJ. Sleep disorders. Med Clin North Am 2003; 87: 803-33.

5. Zonato AI, Bittencourt LR, Martinho FL, Júnior JF, Gregório LC, Tufik S. Association of systematic head and neck physical examination with severity of obstructive sleep apnea-hypopnea syndrome. Laryngoscope 2003; 113: 973-80.

6. Pastor J, Fernández-Lorente J, Ortega B, Galán JM. Comparative analysis of the clinical history and polysomnography in sleep disorders. Diagnostic relevance of polysomnography. Rev Neurol 2001; 32: 22-9.

7. Gondim LM, Matumoto LM, Melo Júnior MA, Bittencourt S, Ribeiro UJ. Comparative study between clinical history and polysomnogram in the obstructive sleep apnea/hypopnea syndrome. Braz J Otorhinolaryngol 2007; 73: 733-7.

8. İzci $B$, Ardıç $S$, Fırat $H$, Şahin A, Altınörs $M$, Karacan İ. Reliability and validity studies of the Turkish version of the Epworth Sleepiness Scale. Sleep Breath 2008; 12: 161-8.

9. Karakoç Ö, Akçam T, Gerek M, Birkent H. Horlama ve obstüriktif uyku apneli hastalarda Epworth uykululuk skalasının güvenilirliği. KBB Forum 2007; 6: 86-9.
10. Hoffstein V, Mateika S. Differences in abdominal and neck circumferences in patients with and without obstructive sleep apnoea. Eur Respir J 1992; 5: 377-81.

11. Borowiecki B, Pollak CP, Weitzman ED, Rakoff S, Imperato J. Fibro-optic study of pharyngeal airway during sleep in patients with hypersomnia obstructive sleep-apnea syndrome. Laryngoscope 1978; 88: 1310-3

12. Terris DJ, Hanasono MM, Liu YC. Reliability of the Muller maneuver and its association with sleep-disordered breathing. Laryngoscope 2000; 110: 1819-23.

13. Faber CE, Grymer L, Norregaard O, Hilberg O. Flextube reflectometry for localization of upper airway narrowing-a preliminary study in models and awake subjects. Respir Med 2001; 95: 631-8.

14. Skatvedt $\mathbf{O}$. Localization of site of obstruction in snorers and patients with obstructive sleep apnea syndrome: a comparison of fiberoptic nasopharyngoscopy and pressure measurements. Acta Otolaryngol 1993; 113: 206-9.

15. Woodson BT, Wooten MR. Comparison of upper-airway evaluations during wakefulness and sleep. Laryngoscope 1994; 104: 821-8.

16. Doghramji K, Jabourian ZH, Pilla M, Farole A, Lindholm RN. Predictors of outcome for uvulopalatopharyngoplasty. Laryngoscope 1995; 105: 311-4.

17. Pang KP, Terris DJ, Podolsky R. Severity of obstructive sleep apnea: correlation with clinical examination and patient perception. Otolaryngol Head Neck Surg 2006; 135: 555-60.

18. Hori Y, Shizuku H, Kondo A, Nakagawa H, Kalubi B, Takeda N. Endoscopic evaluation of dynamic narrowing of the pharynx by the Bernouilli effect producing maneuver in patients with obstructive sleep apnea syndrome. Auris Nasus Larynx 2006; 33: 429-32.

19. Santaolalla Montoya F, Iriondo Bedialauneta JR, Aguirre Larracoechea U, Martinez Ibargüen A, Sanchez Del Rey A, Sanchez Fernandez JM. The predictive value of clinical and epidemiological parameters in the identification of patients with obstructive sleep apnoea (OSA): a clinical prediction algorithm in the evaluation of OSA. Eur Arch Otorhinolaryngol 2007; 264: 63743.

20. Sharma SK, Malik V, Vaudev C, et al. Prediction of obstructive sleep apnea in patients presenting to a tertiary care center. Sleep Breath 2006; 10: 147-54.

21. Scharf SM, Garshick E, Brown R, Tishler PV, Tosteson T, McCarley R. Screening for subclinical sleep-disordered breathing. Sleep 1990; 13: 344-53.

Bağlantı Çakışması:

Bağlantı çakıșması bulunmadı̆̆ı belirtilmiștir.

Iletişim Adresi: Dr. Mustafa Sağıt

T.C. SB Şanluurfa Ĕ̆itim ve Araştırma Hastanesi KBB Kliniği

Hastane Cad. Esentepe SANLIURFA

Tel: $+904143131220 / 1881$

e-posta:musagit@yahoo.com 